TITLE:

\title{
Prediction of variation in critical current with applied tensile/bending strain of Bi2223 composite tape from tensile stress- strain curve
}

\section{$\operatorname{AUTHOR}(\mathrm{S}):$}

Ochiai, S.; Okuda, H.; Sugano, M.; Hojo, M.; Osamura, K.

\section{CITATION:}

Ochiai, S....[et al]. Prediction of variation in critical current with applied tensile/bending strain of Bi2223 composite tape from tensile stress-strain curve. Journal of Applied Physics 2010, 107(8): 083904.

\section{ISSUE DATE:}

2010

URL:

http://hdl.handle.net/2433/120798

RIGHT:

(C) 2010 American Institute of Physics 


\title{
Prediction of variation in critical current with applied tensile/bending strain of Bi2223 composite tape from tensile stress-strain curve
}

\author{
S. Ochiai, ${ }^{1, a)}$ H. Okuda, ${ }^{1}$ M. Sugano, ${ }^{1}$ M. Hojo, ${ }^{1}$ and K. Osamura ${ }^{2}$ \\ ${ }^{1}$ Graduate School of Engineering, Kyoto University, Sakyo-ku, Kyoto 606-8501, Japan \\ ${ }^{2}$ Research Institute for Applied Sciences, Sakyo-ku, Kyoto 606-8202, Japan
}

(Received 20 January 2010; accepted 8 March 2010; published online 21 April 2010)

\begin{abstract}
An approach to predict the variation in critical current with applied tensile/bending strain of Bi2223/ $\mathrm{Ag} / \mathrm{Ag}$ alloy composite tapes from the tensile stress-strain curves was presented. Three different fabrication-route samples were used to examine the applicability of the present approach. The damage strain parameter, referring to the difference between the tensile fracture strain and residual strain of Bi2223 filaments along the sample length direction (current transport direction), was estimated from the variation in the slope of the tensile stress-strain curve. With the estimated damage strain parameter, the irreversible tensile strain for critical current was predicted, which agreed well with the experimental result in all samples. Also by substituting the estimated damage strain parameter into the core shape-incorporated model, the critical current-bending strain curve was predicted, which described satisfactorily the experimental result in all samples. The present approach could be a useful tool for prediction of critical current-dependence on applied tensile/ bending strain. (C) 2010 American Institute of Physics. [doi:10.1063/1.3380828]
\end{abstract}

\section{INTRODUCTION}

Under applied tensile/bending strain, the critical current of Bi2223 composite tape is reduced beyond the irreversible strain due to the damage evolution of the Bi2223 filaments. ${ }^{1-28}$ In case of application of tensile strain $\varepsilon_{\mathrm{T}}$ to samples, the critical current is reversible up to the irreversible strain $\varepsilon_{\mathrm{T}, \text { irr }}$ at which the damage of the Bi2223 filaments takes place. The $\varepsilon_{\mathrm{T}, \text { irr }}$ is given by $\varepsilon_{\mathrm{f}}-\varepsilon_{\mathrm{r}},{ }^{2,4-6,10-17,26-28}$ where $\varepsilon_{\mathrm{f}}$ is the tensile fracture strain of bare Bi2223 filaments in the sample length direction (current transport direction) and $\varepsilon_{\mathrm{r}}$ is the residual strain of Bi2223 filaments in composite tape also in the sample length direction. The residual strain $\varepsilon_{\mathrm{r}}$ is introduced during cooling from heat-treatment temperature in processing due to the difference in coefficient of thermal expansion among the constituents (Bi2223, Ag, and Ag alloy). ${ }^{1-8,10-18,24,26-28}$

In case of application of bending strain $\varepsilon_{\mathrm{B}}$ to samples, the tensile strain in the sample length direction plays a dominant role for damage evolution. ${ }^{7,8,19,20,24-29}$ On this point, the tensile damage behavior is related to the bending one, and $\varepsilon_{\mathrm{f}}-\varepsilon_{\mathrm{r}}$ is a common key parameter for damage evolution under applied tensile and bending strains. From this viewpoint, $\varepsilon_{\mathrm{f}}-\varepsilon_{\mathrm{r}}$ is hereafter called "damage strain parameter." Recently, the authors have attempted to describe the relation of normalized critical current $I_{\mathrm{c}} / I_{\mathrm{c} 0}$ to applied bending strain $\varepsilon_{\mathrm{B}}$ by modeling approach, ${ }^{26-28}$ where $I_{\mathrm{c}}$ is the critical current under applied strain and $I_{\mathrm{c} 0}$ is the original critical current under no applied strain. In the modeling, the shape of the superconducting core, in which the Bi2223 filaments that transport superconducting current are bundled into $\mathrm{Ag}$, was combined with $\varepsilon_{\mathrm{f}}-\varepsilon_{\mathrm{r}}$ and the exerted tensile strain distribu-

${ }^{a)}$ Electronic mail: shojiro.ochiai@materials.mbox.media.kyoto-u.ac.jp. tion in the bent sample (details will be presented in Sec. III). It was shown that such an approach can describe well the $I_{\mathrm{c}} / I_{\mathrm{c} 0}-\varepsilon_{\mathrm{B}}$ relation.

Thus, the estimation of the damage strain parameter $\varepsilon_{\mathrm{f}}-\varepsilon_{\mathrm{r}}$ is a key issue for description and prediction of the irreversible tensile strain for critical current and the critical current-bending strain relation. In the present work, it was attempted to estimate the $\varepsilon_{\mathrm{f}}-\varepsilon_{\mathrm{r}}$ value from the change in the stress carrying capacity of the composite in the tensile stress-strain curve, based on the phenomenon "the stress carrying capacity of the composite is reduced in comparison with that of the assumed case where no filaments are damaged." ${ }^{, 13,17,26,29-31}$ Then it was examined whether the $\varepsilon_{\mathrm{f}}$ $-\varepsilon_{\mathrm{r}}$ value estimated from the stress-strain curve can describe the measured irreversible strain under applied tensile strain and the measured critical current-bending strain relation under applied bending strain. It will be shown that the present approach can describe satisfactorily the experimental results and could be a useful tool for prediction of variation in critical current with applied tensile/bending strain.

\section{EXPERIMENTAL DETAILS}

\section{A. Samples}

For test, three types of Bi2223/Ag/Ag alloy composite tape, designated as VAM1, VAM2, and VAM3 samples in the round-robin tests of VAMAS (Versailles project on advanced materials and standard)/TWA 16 (Technical working area 16, superconducting materials), ${ }^{21,22}$ were used. These samples were supplied by different companies. They each had different architecture, ${ }^{21,24}$ as shown in Figs. 1(a)-1(c), where the optical micrographs of the transverse cross-sections of VAM1, VAM2, and VAM3 samples are presented, respectively. In this figure, the thickness direction is three times enlarged to show clearly the shape of the superconducting 


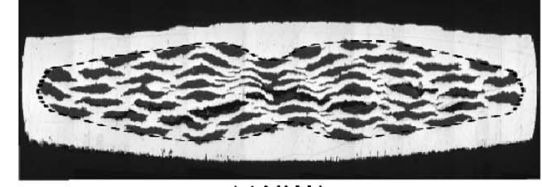

(a) VAM1

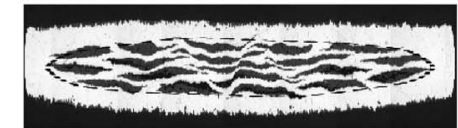

(b) VAM2

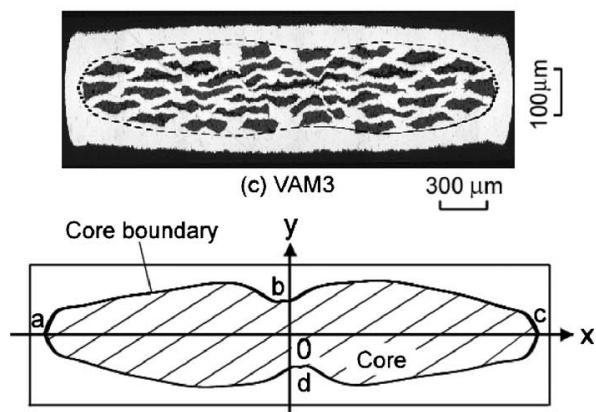

(a') VAM1

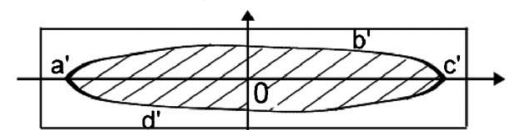

(b') VAM2

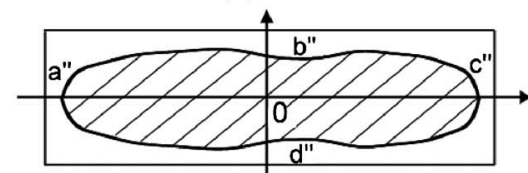

(c') VAM3

FIG. 1. Micrographs of the transverse cross-section of (a) VAM1, (b) VAM2, and (c) VAM3 samples, in which the thickness direction is three times enlarged from the as-observed ones, and the schematic representation of the shape of the core of $\left(\mathrm{a}^{\prime}\right)$ VAM1, ( $\left.\mathrm{b}^{\prime}\right)$ VAM2, and $\left(\mathrm{c}^{\prime}\right)$ VAM3, together with the definition of $x$ and $y$.

core (the region in which the Bi2223 filaments are bundled into Ag). The VAM1, VAM2, and VAM3 samples, containing 57, 19, and 37 Bi2223 filaments in the core, had the overall width $(W)$ of $3.70,2.95$, and $3.14 \mathrm{~mm}$ and overall thickness $(t)$ of $0.270,0.182$, and $0.254 \mathrm{~mm}$, respectively. ${ }^{21}$ With these different types of samples, it was examined comprehensively whether the present approach is utilized or not for prediction of the irreversible tensile strain and critical current-bending relation.

\section{B. Measurement of critical current}

The measurement of the critical current $I_{\mathrm{c}}$ under the applied tensile strain was carried out at $77 \mathrm{~K}$. In this test, tensile strain was applied to the longitudinal direction (current transport direction) at $77 \mathrm{~K}$ with an Instron-type machine. The strain of the composite tape was measured with the very light weight-extensometer developed by Nyilas. ${ }^{14}$ Critical current $I_{\mathrm{c}}$ was measured with a criterion of $1 \mu \mathrm{V} / \mathrm{cm}$ in the self magnetic field.

The measurement of critical current of bent specimens was carried out with the procedure employed in the round robin test. ${ }^{21,22}$ Bending strain was given at room temperature by pressing the sample with the upper GFRP (glass fiber reinforced plastics) die to the lower one with the same cur- vature. The bending strain $\varepsilon_{\mathrm{B}}$ (=tensile strain of the outer surface of the composite in the tensile side) was given by $\varepsilon_{\mathrm{B}}=t /(2 R)$ where $R$ is the radius of the die. Six pairs of dies with the radius $R=\infty$ (straight dies), 61.6, 34.0, 22.3, 17.3, and $13.8 \mathrm{~mm}$ were used to give bending strain, corresponding to $\varepsilon_{\mathrm{B}}=0 \%, 0.2 \%, 0.4 \%, 0.6 \%, 0.8 \%$, and $1.0 \%$ for VAM1, $\varepsilon_{\mathrm{B}}=0 \%, 0.13 \%, 0.26 \%, 0.40 \%, 0.54 \%$, and $0.67 \%$ for VAM2, and $\varepsilon_{\mathrm{B}}=0 \%, 0.19 \%, 0.38 \%, 0.56 \%, 0.75 \%$, and $0.94 \%$ for VAM3, respectively. The samples bent at room temperature were cooled to $77 \mathrm{~K}$, at which the critical current $I_{\mathrm{c}}$ was measured in the same manner to that of the samples pulled in tension. After the measurement of the critical current at a given bending strain, the samples were warmed to room temperature, at which the bending strain was raised to the next prescribed one. The samples with an increased bending strain were again cooled to $77 \mathrm{~K}$ for measurement of critical current. Such a procedure was repeated to obtain the critical current-bending strain relation. The experimental results have been reported in our preceding work. ${ }^{26}$ The results are analyzed in the present work.

\section{Measurement of tensile stress-strain curve and derivation of the slope of the measured stress- strain curve}

Tensile test of VAM1, VAM2, and VAM3 samples was carried out with a universal testing machine (Autograph AG$50 \mathrm{kNG}$, Shimadzu, Japan) at a strain rate of $2 \times 10^{-4} / \mathrm{s}$ at room temperature and $77 \mathrm{~K}$ for a gage length $25 \mathrm{~mm}$. Tensile strain was applied in the longitudinal direction (current transport direction). The strain of the composite tape was measured with very light weight-extensometers developed by Nyilas $^{14}$ as well as the strain during measurement of critical current under applied tensile strain.

Tensile damage was given to the samples directly at $77 \mathrm{~K}$ and the critical current was measured at the same temperature, as stated in B above. For estimation of the damage strain parameter $\varepsilon_{\mathrm{f}}-\varepsilon_{\mathrm{r}}$ that determines directly the irreversible tensile strain $\varepsilon_{\mathrm{T}, \text { irr }}$ for critical current, ${ }^{1-8,10-12,15-19}$ the stress-strain curve was measured at $77 \mathrm{~K}$.

On the other hand, the samples bent at room temperature were cooled to $77 \mathrm{~K}$ for measurement for critical current. After the measurement of critical current, they were warmed to room temperature to give the next prescribed bending strain, as stated in B above. In the process of critical currentbending strain relation measurement, when the specimens are cooled to $77 \mathrm{~K}$, compressive strain is added to the Bi2223 filaments in the current transport direction due to the higher coefficient of thermal expansion of metallic constituents (Ag and $\mathrm{Ag}$ alloy) than that of Bi2223 filaments. ${ }^{1-8,10-17,24,26-28}$ As the damage of filaments in the bent specimens is caused by the tensile strain in the current transport direction, the filaments have been damaged by the bending-induced tensile strain at room temperature. The additionally exerted compressive strain on filaments at $77 \mathrm{~K}$ due to cooling does not cause further damage. The damage of the filaments at room temperature is conserved at $77 \mathrm{~K}$, and hence, the critical current at $77 \mathrm{~K}$ is determined by the damage at room temperature. $7,16,17,24$ 
Due to the reason stated above, the stress-strain curve for prediction of the variation in critical current with bending strain was measured at room temperature. It is noted here that, as the Ag in the composite tapes is soft, it is yielded in tension at room temperature in the initial state where the samples are cooled from the heat-treatment temperature to room one due to the difference in coefficient of thermal expansion among the constituents. ${ }^{1-8,10-18,24,26-28}$ When the samples are further cooled to $77 \mathrm{~K}, \mathrm{Ag}$ keeps the tensileyielded state also at $77 \mathrm{~K}$. When the sample is warmed from $77 \mathrm{~K}, \mathrm{Ag}$ comes to be yielded in compression on the way from $77 \mathrm{~K}$ to room temperature. Accordingly, once the samples are cooled to $77 \mathrm{~K}$ and then warmed to room temperature, $\mathrm{Ag}$ is yielded in compression at room temperature, ${ }^{15,16}$ whereas, it is yielded in tension at room temperature in the initial state. As a result, the residual strain $\left(\varepsilon_{\mathrm{r}}\right)$ of Bi2223 filaments at room temperature becomes different when such a thermal history is added. Due to such a reason, for estimation of $\varepsilon_{\mathrm{f}}-\varepsilon_{\mathrm{r}}$ value to predict the relation of the critical current (measured at $77 \mathrm{~K}$ ) to bending strain (given at room temperature), the stress-strain curve was measured at room temperature for the samples that had been cooled to $77 \mathrm{~K}$ and then warmed to room temperature.

In the tensile test, the data sets of (strain $\varepsilon_{\mathrm{T}}$, stress $\sigma_{\mathrm{T}}$ ) were obtained in steps of $0.0005 \%$ strain. The slope $\mathrm{d} \sigma_{\mathrm{T}} / \mathrm{d} \varepsilon_{\mathrm{T}}$ at $\varepsilon_{\mathrm{T}}$ was estimated from the slope of the stress-strain curve in the range of $\varepsilon_{\mathrm{T}}-0.005 \%$ to $\varepsilon_{\mathrm{T}}+0.005 \%$ by a least square method. The $\varepsilon_{\mathrm{f}}-\varepsilon_{\mathrm{r}}$ value was read from the $\mathrm{d} \sigma_{\mathrm{T}} / \mathrm{d} \varepsilon_{\mathrm{T}}-\varepsilon_{\mathrm{T}}$ curve by the procedure shown later in Sec. IV for tensile damage and in Secs. V and VI for bending damage.

\section{PROCEDURE FOR PREDICTION OF CRITICAL CURRENT-BENDING STRAIN RELATION}

The shapes of the core of VAM1, VAM2, and VAM3 samples in Figs. 1(a)-1(c) are schematically drawn in Figs. $1\left(a^{\prime}\right)-1\left(c^{\prime}\right)$, respectively. The shape is different to each other. Recently, the authors attempted to incorporate the practical shape of the core in the modeling and found that the measured critical current-bending strain relation could be described well by such a core shape-incorporated model (hereafter noted as model S). ${ }^{26-28}$ Also, another model, in which the shape of the core is approximated to be rectangular, has been used for analysis of critical current-bending strain relation. $8,27,28$ Such an approximated model is hereafter noted as model R (rectangular model). Figure 2 shows the schematic representation of (a) model $\mathrm{S}$ and (b) model $\mathrm{R}$ for VAM1 as an example, where $t$ is the thickness of the sample and $W_{\text {core }}$ is the width of the core. The value of $W_{\text {core }}$ and the cross-sectional area of the core are common for both models. The outline of the procedure to analyze the critical currentbending strain relation by models $\mathrm{S}$ and $\mathrm{R}$ in combination with the $\varepsilon_{\mathrm{f}}-\varepsilon_{\mathrm{r}}$ value is presented below.

\section{A. Formulation of the shape of the superconducting core in the cross-section}

The shapes of the core of VAM1, VAM2, and VAM3 have been shown in Fig. 1. Taking the width- and thicknessdirections of the composite tape as $x$ and $y$, respectively, and

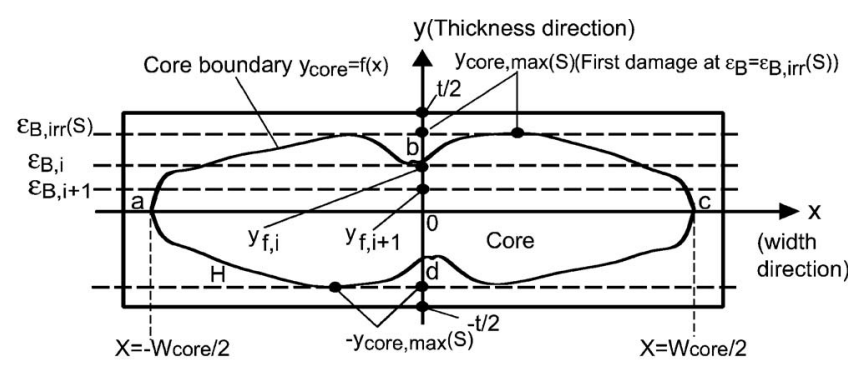

(a) Model S

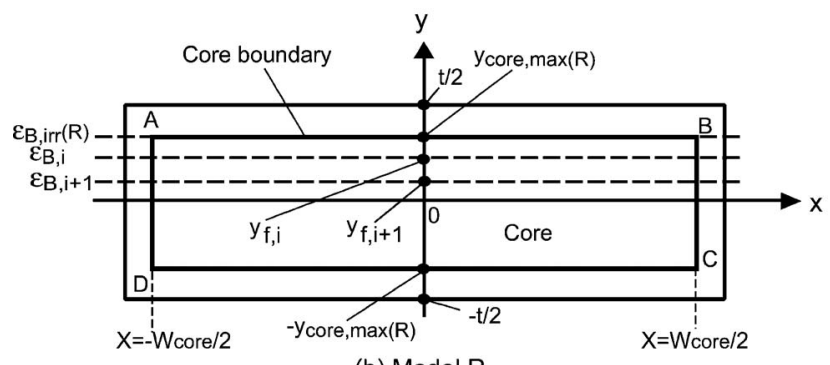

(b) Model R

FIG. 2. Schematic representation of the geometry of the cross-section and the relation of the damage front $\left(y_{\text {core, max }}, y_{\mathrm{f}, \mathrm{i}}\right.$, and $\left.y_{\mathrm{f}, \mathrm{i}+1}\right)$ to bending strain $\left(\varepsilon_{\mathrm{B}, \mathrm{irr}}, \varepsilon_{\mathrm{B}, \mathrm{i}}\right.$, and $\left.\varepsilon_{\mathrm{B}, \mathrm{i}+1}\right)$ in models (a) S and (b) R for VAM1 as an example.

the center of the composite tape as $x=y=0$ [Figs. $\left.1\left(a^{\prime}\right)-1\left(c^{\prime}\right)\right]$ we formulated the shapes of the core (abcda for VAM1, $a^{\prime} b^{\prime} c^{\prime} d^{\prime} a^{\prime}$ for VAM2, and $a^{\prime \prime} b^{\prime \prime} c^{\prime \prime} d^{\prime \prime} a^{\prime \prime}$ for VAM3) in model $\mathrm{S}$ by ninth order polynomial, as in our preceding work. ${ }^{26,27}$ The formulations obtained for model $\mathrm{S}$ are listed in Table I, where the $y$-coordinate of the boundary of the core, $y_{\text {core }}$, is given as a function of $x$. The boundaries of the core for model R, where the complex shape of the core is approximated to be rectangular for simplicity, are also listed in Table I.

\section{B. Calculation of the relation of the normalized critical current $I_{\mathrm{c}} / I_{\mathrm{c} 0}$ to bending strain $\varepsilon_{\mathrm{B}}$}

The cross-section and the relation of bending strain $\varepsilon_{\mathrm{B}}$ to the damage front $y_{\mathrm{f}}$ in VAM1 are shown in Figs. 2(a) and 2(b) for models $S$ and $R$, respectively. When the bending strain $\varepsilon_{\mathrm{B}}$ reaches the irreversible strain $\varepsilon_{\mathrm{B}, \text { irr }},\left[\varepsilon_{\mathrm{B}, \text { irr }}(\mathrm{S})\right.$ and $\varepsilon_{B, \text { irr }}(R)$ for models $S$ and $R$, respectively], the damage to reduce the critical current takes place first at the outermost filaments at the maximum value of $y_{\text {core }}, y_{\text {core, } \max }\left[y_{\text {core, max }}(\mathbf{S})\right.$ and $y_{\text {core, } \max }(\mathrm{R})$ for models $\mathrm{S}$ and $\mathrm{R}$, respectively]. The $y_{\text {core, } \max }(\mathrm{S})$ values were measured to be $0.117,0.0696$, and $0.0972 \mathrm{~mm}$, and the $y_{\text {core, } \max }(\mathrm{R})$ ones were $0.0918,0.0540$, and $0.0809 \mathrm{~mm}$, for VAM1, VAM2, and VAM3, respectively. When the bending strain $\left(\varepsilon_{\mathrm{B}} \geq \varepsilon_{\mathrm{B}, \text { irr }}\right)$ is raised from $\varepsilon_{\mathrm{B}, i}$ to $\varepsilon_{\mathrm{B}, i+1}$, the damage front $y_{\mathrm{f}}$ moves from $y_{\mathrm{f}, i}$ to $y_{\mathrm{f}, i+1}$, resulting in reduction in the cross-sectional area of the current transporting Bi2223 filaments. In both models $\mathrm{S}$ and $\mathrm{R}$, the damage front $y_{\mathrm{f}}$ is expressed by ${ }^{17,26-28}$

$$
y_{\mathrm{f}}=\frac{(t / 2)\left(\varepsilon_{\mathrm{f}}-\varepsilon_{\mathrm{r}}\right)}{\varepsilon_{\mathrm{B}}} .
$$

Damage takes place first at $y_{\mathrm{f}}=y_{\text {core,max }}$ when $\varepsilon_{\mathrm{B}}$ reaches an irreversible bending strain $\varepsilon_{\mathrm{B}, \text { irr }}$. Substituting $y_{\mathrm{f}}=y_{\text {core, max }}$ and $\varepsilon_{\mathrm{B}}=\varepsilon_{\mathrm{B}, \text { irr }}$ into Eq. (1), we have 
TABLE I. Formulated shape (boundary) of the core in models S and R. The length unit is $\mathrm{mm}$.

Formulated shape (boundary) of the core $y_{\text {core }}=f(x)$ in model S (abcda, $a^{\prime} b^{\prime} c^{\prime} d^{\prime} a^{\prime}, a^{\prime \prime} b^{\prime \prime} c^{\prime \prime} d^{\prime \prime} a^{\prime \prime}$ in Figs. $1\left(a^{\prime}\right)-1\left(c^{\prime}\right)$ for VAM1, VAM2 and VAM3, respectively.)

ab $: y_{\text {core }}=0.117324+1.13901 x+10.0985 x^{2}+38.6006 x^{3}$ $+83.9271 x^{4}+113.805 x^{5}+97.9306 x^{6}+51.8601 x^{7}$ $+15.3722 x^{8}+1.94706 x^{9}$ for $-1.76<x<-0.017$ bc: $y_{\text {core }}=0.0765863+0.132501 x+1.36795 x^{2}-11.2465 x^{3}$ $+36.2954 x^{4}-63.3049 x^{5}+64.1326 x^{6}-37.7293 x^{7}$ $+11.9598 x^{8}-1.58008 x^{9}$ for $-0.017<x<+1.76$

VAM1 cda: point symmetry of abc in $x=y=0$ $\mathrm{a}^{\prime} \mathrm{b}^{\prime} \mathrm{c}^{\prime}: y_{\text {core }}=0.0673640-0.0141873 x-0.0000520952 x^{2}$ $+0.0470280 x^{3}-0.0594494 x^{4}-0.0487762 x^{5}+0.0612979 x^{6}$ $+0.0222239 x^{7}-0.0215074 x^{8}-0.00397922 x^{9}$ for $-1.36 \leq x \leq+1.36$

VAM2 $\mathrm{c}^{\prime} \mathrm{d}^{\prime} \mathrm{e}^{\prime}$ : point symmetry of $\mathrm{a}^{\prime} \mathrm{b}^{\prime} \mathrm{c}^{\prime}$ in $x=y=0$ $\mathrm{a}^{\prime \prime} \mathrm{b}^{\prime \prime}: y_{\text {core }}=0.0856473-0.0466775 x+0.120101 x^{2}$ $+0.304117 x^{3}-0.773348 x^{4}-2.03475 x^{5}-0.395264 x^{6}$ $+2.18236 x^{7}+1.95785 x^{8}+0.502644 x^{9}$ for $-1.498 \leq x \leq+0.207$ $\mathrm{b}^{\prime \prime} \mathrm{c}^{\prime \prime}: y_{\text {core }}=0.206362-2.32096 x+18.2998 x^{2}-80.0315 x^{3}$ $+211.859 x^{4}-348.562 x^{5}+356.842 x^{6}-220.644 x^{7}$ $+75.3420 x^{8}-10.9023 x^{9}$ for $+0.207 \leq x \leq+1.498$

VAM3 $c^{\prime \prime} d^{\prime \prime} a^{\prime \prime}$ symmetry with $c^{\prime \prime} b^{\prime \prime} a^{\prime \prime}$ with respect to $x$ axis

Formulated shape (boundary) of the core in model $\mathrm{R}$, in which the shape is approximated to be rectangle [ABCDA in Fig. 2(b)] in all samples

VAM1

$\mathrm{AB}: y_{\text {core }}=0.0918(-1.76 \leq x \leq 1.76)$

BC: $x_{\text {core }}=1.76(-0.0918 \leq y \leq 0.0918)$

$\mathrm{CD}: y_{\text {core }}=-0.0918(-1.76 \leq x \leq 1.76)$,

$\mathrm{DA}: x_{\text {core }}=-1.76(-0.0918 \leq y \leq 0.0918)$

$\mathrm{AB}: y_{\text {core }}=0.0540(-1.36 \leq x \leq 1.36)$,

BC: $x_{\text {core }}=1.36(-0.0540 \leq y \leq 0.0540)$

$\mathrm{CD}: y_{\text {core }}=-0.0540(-1.36 \leq x \leq 1.36)$,

VAM2

$\mathrm{DA}: x_{\text {core }}=-1.36(-0.0540 \leq y \leq 0.0540)$

$\mathrm{AB}: y_{\text {core }}=0.0809(-1.50 \leq x \leq 1.50)$,

BC: $x_{\text {core }}=1.50(-0.0809 \leq y \leq 0.0809)$

CD: $y_{\text {core }}=-0.0809(-1.50 \leq x \leq 1.50)$,

VAM3

DA: $x_{\text {core }}=-1.50(-0.0809 \leq y \leq 0.0809)$

$$
\varepsilon_{\mathrm{B}, \mathrm{irr}}=\left(\frac{t / 2}{y_{\text {core, } \max }}\right)\left(\varepsilon_{\mathrm{f}}-\varepsilon_{\mathrm{r}}\right) .
$$

The normalized critical current $I_{\mathrm{c}} / I_{\mathrm{c} 0}\left(I_{\mathrm{c}}\right.$ is the critical current at arbitrary bending strain $\varepsilon_{\mathrm{B}}$ and $I_{\mathrm{c} 0}$ is the original critical current at $\varepsilon_{\mathrm{B}}=0 \%$ ) is given by unity for $\varepsilon_{\mathrm{B}} \leq \varepsilon_{\mathrm{B} \text {,irr }}$, and it decreases with increasing $\varepsilon_{\mathrm{B}}$ for $\varepsilon_{\mathrm{B}, \text { irr }} \leq \varepsilon_{\mathrm{B}}$. The $I_{\mathrm{c}} / I_{\mathrm{c} 0}-\varepsilon_{\mathrm{B}}$ relations in models $\mathrm{S}$ and $\mathrm{R}$ are expressed by ${ }^{27}$ model S

$$
\begin{aligned}
\frac{I_{\mathrm{c}}}{I_{\mathrm{c} 0}}=1 \text { for } \varepsilon_{\mathrm{B}} \leq \varepsilon_{\mathrm{B}, \text { irr }}, \\
\frac{I_{\mathrm{c}}}{I_{\mathrm{c} 0}}=1-\int_{-W_{\text {core }} / 2}^{W_{\mathrm{core}^{/ 2}}\left[y_{\text {core }}\right.} \\
\left.-\left\{\frac{(t / 2)\left(\varepsilon_{\mathrm{f}}-\varepsilon_{\mathrm{r}}\right)}{\varepsilon_{\mathrm{B}}}\right\}\right] \mathrm{d} x / S_{\text {core }} \text { for } \varepsilon_{\mathrm{B}, \text { irr }} \leq \varepsilon_{\mathrm{B}},
\end{aligned}
$$
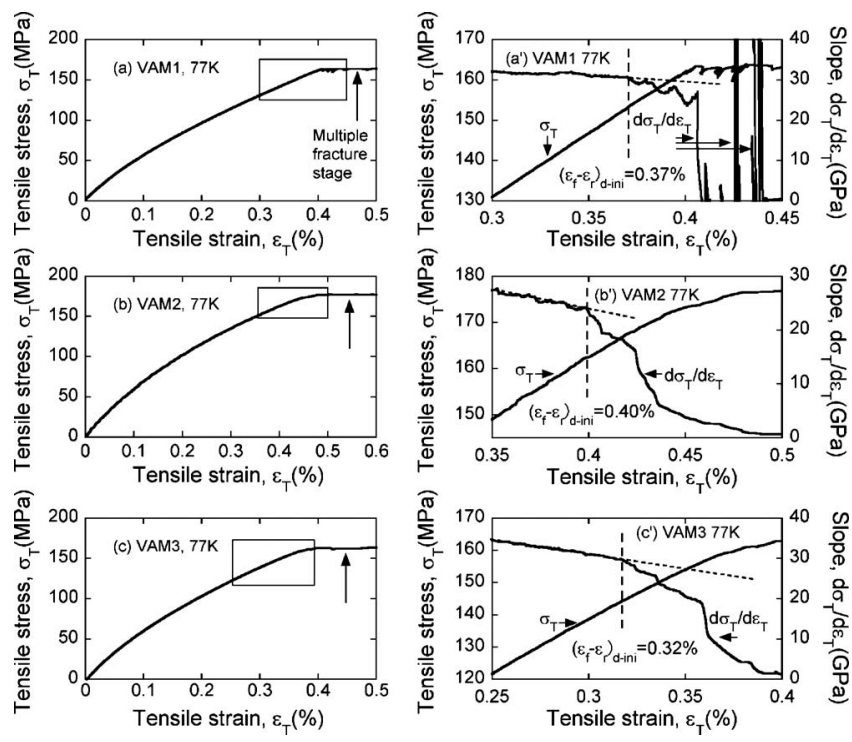

FIG. 3. Measured tensile stress $\left(\sigma_{\mathrm{T}}\right)$-strain $\left(\varepsilon_{\mathrm{T}}\right)$ curves of (a) VAM1, (b) VAM2, and (c) VAM3 samples at $77 \mathrm{~K}$. The arrows show the stage of multiple fracture of the Bi2223 filaments. The stress-strain curve and the slope of the regions surrounded by the rectangles in (a), (b), and (c), where damages initiate and extend, are presented at high magnification in $\left(\mathrm{a}^{\prime}\right)$, $\left(b^{\prime}\right)$, and $\left(c^{\prime}\right)$, respectively. The $\left(\varepsilon_{\mathrm{f}}-\varepsilon_{\mathrm{r}}\right)_{\mathrm{d}-\mathrm{ini}}$ refers to the damage strain parameter at initiation of damage of Bi2223 filaments.

$$
\begin{aligned}
& \frac{I_{\mathrm{c}}}{I_{\mathrm{c} 0}}=1 \quad \text { for } \quad \varepsilon_{\mathrm{B}} \leq \varepsilon_{\mathrm{B}, \mathrm{irr}}, \\
& \frac{I_{\mathrm{c}}}{I_{\mathrm{c} 0}}=\frac{1}{2}\left[1+\left(\frac{t / 2}{y_{\text {core } \max }}\right)\left(\frac{\varepsilon_{\mathrm{f}}-\varepsilon_{r}}{\varepsilon_{\mathrm{B}}}\right)\right] \quad \text { for } \quad \varepsilon_{\mathrm{B}, \text { irr }} \leq \varepsilon_{\mathrm{B}},
\end{aligned}
$$

where $S_{\text {core }}$ is the cross-sectional area of the core $(0.646$, 0.294 and $0.485 \mathrm{~mm}^{2}$ measured for VAM1, VAM2, and VAM3, respectively). Substituting the $\varepsilon_{\mathrm{f}}-\varepsilon_{\mathrm{r}}$ values of VAM1, VAM2, and VAM3 estimated from the stress-strain curves into Eqs. (2)-(4), the $I_{\mathrm{c}} / I_{\mathrm{c} 0}-\varepsilon_{\mathrm{B}}$ relation can be calculated.

\section{ESTIMATION OF THE DAMAGE STRAIN PARAMETER FROM THE VARIATION IN SLOPE OF STRESS-STRAIN CURVES AT $77 \mathrm{~K}$ AND ITS APPLICATION TO PREDICTION OF THE TENSILE IRREVERSIBLE STRAIN $\varepsilon_{\mathrm{T}, \text { irr }}$ FOR CRITICAL CURRENT}

\section{A. Estimation of the damage strain parameter from the variation in slope of stress-strain curves at $77 \mathrm{~K}$}

Figure 3 shows the measured tensile stress $\left(\sigma_{\mathrm{T}}\right)$-strain $\left(\varepsilon_{\mathrm{T}}\right)$ curves of (a) VAM1, (b) VAM2, and (c) VAM3 samples at $77 \mathrm{~K}$. All samples show the common feature on the point that the samples deform at nearly constant stress at high strain ranges $\left(\varepsilon_{\mathrm{T}}>0.4 \%, 0.5 \%\right.$, and $0.4 \%$ for VAM1, VAM2, and VAM3, respectively). The reason for this is accounted for as follows. ${ }^{29-31}$ In the initial stage of filament fracture, the weakest filament is fractured first and then the second, third,... weakest ones. In and after such an initial stage, as the stress is transferred also to the once-fractured filaments

model R 
through the filament/silver interface, the once-fractured filaments are again fractured. As a result, the filaments exhibit multiple-fracture within the gauge length, as has been observed in the filamentary composite tapes. ${ }^{8,9,12,31}$ In such a stage, the fracture-induced reduction in stress carrying capacity of the filaments is balanced with the strain hardeninginduced increase in stress carrying capacity of the $\mathrm{Ag}$ and $\mathrm{Ag}$ alloy, leading to the nearly constant stress of the composite. $^{12,17}$

The filament damage initiates in advance of such a stress-constant stage. The stress-strain range covering the damage initiation stage is shown with rectangle [Figs. 3(a)-3(c)]. The stress $\left(\sigma_{\mathrm{T}}\right)$-strain $\left(\varepsilon_{\mathrm{T}}\right)$ curves in the rectangles and their variations in the slope $\mathrm{d} \sigma_{\mathrm{T}} / \mathrm{d} \varepsilon_{\mathrm{T}}$ with strain $\varepsilon_{\mathrm{T}}$ are shown in Figs. 3( $\left.\mathrm{a}^{\prime}\right)-3\left(\mathrm{c}^{\prime}\right)$, respectively. At $\varepsilon_{\mathrm{T}}=0 \%$, the strain of the Bi2223 filaments is $\varepsilon_{\mathrm{r}}$ (compressive and therefore negative $\left.{ }^{1-8,10,11,15-17,26-28}\right)$. With increasing $\varepsilon_{\mathrm{T}}$, the strain of the filaments becomes zero at $\varepsilon_{\mathrm{T}}=-\varepsilon_{\mathrm{r}}$ and becomes $\varepsilon_{\mathrm{f}}$ (fracture strain of the filaments) at $\varepsilon_{\mathrm{T}}=\varepsilon_{\mathrm{f}}-\varepsilon_{\mathrm{r}}$. We note the damage strain parameter, corresponding to the tensile strain at which the reduction in slope initiates, as $\left(\varepsilon_{\mathrm{f}}-\varepsilon_{\mathrm{r}}\right)_{\mathrm{d} \text {-ini }}$ The values of $\left(\varepsilon_{\mathrm{f}}-\varepsilon_{\mathrm{r}}\right)_{\mathrm{d}-\mathrm{ini}}$ indicated in Figs. 3( $\left.\mathrm{a}^{\prime}\right)-3\left(\mathrm{c}^{\prime}\right)$ correspond to the damage initiation of Bi2223 filaments in VAM1, VAM2, and VAM3, respectively, due to the following reason.

The $\mathrm{Ag}$ at $77 \mathrm{~K}$ has been yielded in tension even at $\varepsilon_{\mathrm{T}}$ $=0 \%$ due to the thermally induced stress during cooling to $77 \mathrm{~K} .{ }^{4-6,10-12,16,17,24}$ Also Ag alloy deforms plastically in the applied strain ranges in Figs. $3\left(\mathrm{a}^{\prime}\right)-3\left(\mathrm{c}^{\prime}\right)$ in the present VAM1, VAM2, and VAM3 samples. ${ }^{10}$ The slope $\mathrm{d} \sigma_{\mathrm{T}} / \mathrm{d} \varepsilon_{\mathrm{T}}$ of the composite under plastically deforming $\mathrm{Ag}$ and $\mathrm{Ag}$ alloy is expressed by

$$
\mathrm{d} \sigma_{\mathrm{T}} / \mathrm{d} \varepsilon_{\mathrm{T}}=E_{\mathrm{Bi}} V_{\mathrm{Bi}}+\left(\mathrm{d} \sigma_{\mathrm{Ag}} / \mathrm{d} \varepsilon_{\mathrm{T}}\right) V_{\mathrm{Ag}}+\left(\mathrm{d} \sigma_{\text {Alloy }} / \mathrm{d} \varepsilon_{\mathrm{T}}\right) V_{\text {Alloy }}
$$

where $E$ is the Young's modulus, $\sigma$ the stress, and $V$ the volume fraction, and the subscripts $\mathrm{Bi}, \mathrm{Ag}$, and Alloy refer to the Bi2223 filaments, Ag, and Ag alloy, respectively. The terms $\mathrm{d} \sigma_{\mathrm{Ag}} / \mathrm{d} \varepsilon_{\mathrm{T}}$ and $\mathrm{d} \sigma_{\text {Alloy }} / \mathrm{d} \varepsilon_{\mathrm{T}}$ decrease with increasing $\varepsilon_{\mathrm{T}}$, which is a general feature of metals. Accordingly, when no filaments are fractured (namely when $E_{\mathrm{Bi}} V_{\mathrm{Bi}}$ is constant), the $\mathrm{d} \sigma_{\mathrm{T}} / \mathrm{d} \varepsilon_{\mathrm{T}}$ decreases with increasing $\varepsilon_{\mathrm{T}}$ due to the decrease in $\mathrm{d} \sigma_{\mathrm{Ag}} / \mathrm{d} \varepsilon_{\mathrm{T}}$ and $\mathrm{d} \sigma_{\mathrm{Alloy}} / \mathrm{d} \varepsilon_{\mathrm{T}}$.

At $\varepsilon_{\mathrm{T}}=\left(\varepsilon_{\mathrm{f}}-\varepsilon_{\mathrm{r}}\right)_{\mathrm{d}-\mathrm{ini}}$, the slope $\left(\mathrm{d} \sigma_{\mathrm{T}} / \mathrm{d} \varepsilon_{\mathrm{T}}\right)$ values are roughly read to be 30,25 , and $30 \mathrm{GPa}$ for VAM1, VAM2, and VAM3, respectively. The Young's modulus $E_{\mathrm{Bi}}$ of the Bi2223 filaments in the present and similar Bi2223/Ag/Ag alloy composite tapes has been estimated to be $90-110$ $\mathrm{GPa}^{10-12}$ The volume fraction of the Bi2223 filaments $V_{\mathrm{Bi}}$ has been measured to be $0.27,0.25$, and 0.29 for VAM1, VAM2, and VAM3, respectively. ${ }^{10,21}$ If we take $E_{\mathrm{Bi}}$ $=100 \mathrm{GPa}$ as a rough approximation, the $E_{\mathrm{Bi}} V_{\mathrm{Bi}}$ in Eq. (5) is calculated to be 27,25 , and $29 \mathrm{GPa}$ for VAM1, VAM2, and VAM3 samples, respectively, which occupies the major part of the $\mathrm{d} \sigma_{\mathrm{T}} / \mathrm{d} \varepsilon_{\mathrm{T}}$ value at $\varepsilon_{\mathrm{T}}=\left(\varepsilon_{\mathrm{f}}-\varepsilon_{\mathrm{r}}\right)_{\mathrm{d} \text {-ini }}(30,25$, and 30 $\mathrm{GPa})$. This suggests that the $E_{\mathrm{Bi}} V_{\mathrm{Bi}}$ of the Bi2223 filaments contributes dominantly to the $\mathrm{d} \sigma_{\mathrm{T}} / \mathrm{d} \varepsilon_{\mathrm{T}}$ of the composite tape at $\varepsilon_{\mathrm{T}}=\left(\varepsilon_{\mathrm{f}}-\varepsilon_{\mathrm{r}}\right)_{\mathrm{d} \text {-ini. }}$. Accordingly, if the fracture of the filaments starts, the $E_{\mathrm{Bi}} V_{\mathrm{Bi}}$ and therefore the $\mathrm{d} \sigma_{\mathrm{T}} / \mathrm{d} \varepsilon_{\mathrm{T}}$ value de- creases significantly. The significant reduction in $\mathrm{d} \sigma_{\mathrm{T}} / \mathrm{d} \varepsilon_{\mathrm{T}}$

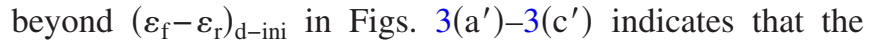
damage of Bi2223 filaments initiates at $\left(\varepsilon_{\mathrm{f}}-\varepsilon_{\mathrm{r}}\right)_{\mathrm{d} \text {-ini }}(=0.37 \%$, $0.40 \%$, and $0.32 \%$ for VAM1, VAM2, and VAM3 samples, respectively). It is noted that the sections with high and low $\varepsilon_{\mathrm{f}}-\varepsilon_{\mathrm{r}}$ values coexist within the specimen. ${ }^{12,23,27,28}$ The damage strain parameter $\left(\varepsilon_{\mathrm{f}}-\varepsilon_{\mathrm{r}}\right)_{\mathrm{d} \text {-ini }}$ estimated from the tensile stress-strain curve corresponds to the local section with the lowest $\varepsilon_{\mathrm{f}}-\varepsilon_{\mathrm{r}}$ value within the volume of the tested specimen.

As the mechanical damage of the Bi2223 filaments is the cause for the reduction in critical current, the reduction in critical current is expected to initiate at $\varepsilon_{\mathrm{T}}=\varepsilon_{\mathrm{T} \text {,irr }}$

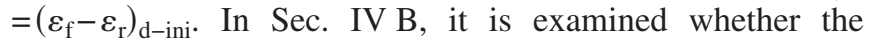
$\left(\varepsilon_{\mathrm{f}}-\varepsilon_{\mathrm{r}}\right)_{\mathrm{d}-\text {-ini }}$ values of VAM1, VAM2, and VAM3 samples estimated from the variation in the slope of the stress-strain curves at $77 \mathrm{~K}$ agree with the experimentally measured irreversible strain $\left(\varepsilon_{\mathrm{T}, \mathrm{irr}}\right)$ values or not.

\section{B. Comparison of the predicted irreversible tensile strain $\varepsilon_{T, \text { irr }}$ for critical current at $77 \mathrm{~K}$ with the experimental ones}

Concerning the change in critical current of Bi2223 composite tape with increasing applied tensile strain $\varepsilon_{\mathrm{T}}$, the following features have been found in the reported results for various samples from different fabrication routes. ${ }^{1,4-8,10-12}$ (a) The critical current is almost constant or decreases slightly with increasing $\varepsilon_{\mathrm{T}}$ even before the initiation of damage. (b) In such an applied tensile strain range, the change in critical current is almost linear with $\varepsilon_{\mathrm{T}}$, while the slope of critical current-applied tensile strain is not common in the reported results, possibly due to the difference in textured structure, grain boundary character, amount of voids and inclusions, thermal and rolling/drawing history and so on among the tested samples. It is noted that, though the slope is different among the tested samples, the slope is particular to a given sample. These results suggest that the initiation of damage that causes the severe decrease in critical current can be read from the measured critical current-tensile strain relation for each sample, by the following procedure.

Figure 4 shows the measured changes of the normalized critical current $I_{\mathrm{c}} / I_{\mathrm{c} 0}$ with increasing applied tensile strain $\varepsilon_{\mathrm{T}}$ in (a) VAM1, (b) VAM2, and (c) VAM3 samples at $77 \mathrm{~K}$. In the present samples, the features mentioned above were also found as shown with the broken lines. The irreversible strain $\varepsilon_{\mathrm{T} \text {,irr }}$, at which damage initiates, corresponds to the strain at which the critical current deviates downward from the broken lines. The region of the $I_{\mathrm{c}} / I_{\mathrm{c} 0}-\varepsilon_{\mathrm{T}}$ relation, in which such a deviation point is included, is surrounded by the rectangles.

The $I_{\mathrm{c}} / I_{\mathrm{c} 0}-\varepsilon_{\mathrm{T}}$ relation of the regions surrounded by the rectangles in Figs. 4(a)-4(c), where damages initiate and extend, are presented at high magnification in Figs. $4\left(a^{\prime}\right)-4\left(c^{\prime}\right)$, respectively. For comparison, the variations of the slope $\mathrm{d} \sigma_{\mathrm{T}} / \mathrm{d} \varepsilon_{\mathrm{T}}$ of the stress-strain curves in the corresponding $\varepsilon_{\mathrm{T}}$ ranges, taken from Figs. $3\left(\mathrm{a}^{\prime}\right)-3\left(\mathrm{c}^{\prime}\right)$, are also presented in Figs. 4( $\left.a^{\prime}\right)-4\left(c^{\prime}\right)$. The damage strain parameter at the damage initiation of the filaments, $\left(\varepsilon_{\mathrm{f}}-\varepsilon_{\mathrm{r}}\right)_{\mathrm{d} \text {-ini }}$, estimated from the slope change in the stress-strain curves $(0.37 \%, 0.40 \%$, and $0.32 \%$ for VAM1, VAM2, and VAM3 samples, respectively) are also shown in Figs. 4( $\left.a^{\prime}\right)-4\left(c^{\prime}\right)$. 

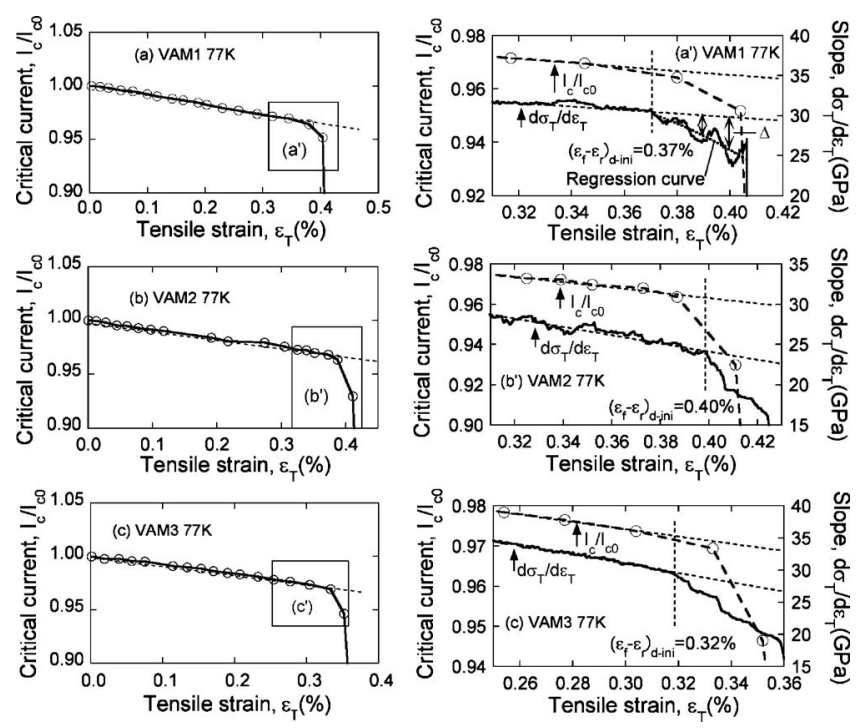

FIG. 4. Measured changes of the normalized critical current $I_{\mathrm{c}} / I_{\mathrm{c} 0}$ with increasing applied tensile strain $\varepsilon_{\mathrm{T}}$ for (a) VAM1, (b) VAM2 and (c) VAM3 samples at $77 \mathrm{~K}$. The $I_{\mathrm{c}} / I_{\mathrm{c} 0}-\varepsilon_{\mathrm{T}}$ relation in the rectangles in (a), (b), and (c) where damages initiate and extend, and the slope $\mathrm{d} \sigma_{\mathrm{T}} / \mathrm{d} \varepsilon_{\mathrm{T}}$-strain $\varepsilon_{\mathrm{T}}$ relation in the corresponding strain range are presented at high magnification in $\left(\mathrm{a}^{\prime}\right)$, $\left(\mathrm{b}^{\prime}\right)$, and $\left(\mathrm{c}^{\prime}\right)$, respectively. The damage strain parameter $\left(\varepsilon_{\mathrm{f}}-\varepsilon_{\mathrm{r}}\right)_{\mathrm{d}-\mathrm{ini}}$ at the damage initiation $(0.37 \%, 0.40 \%$, and $0.32 \%$ for VAM1, VAM2, and VAM3 samples, respectively) estimated from the $\mathrm{d} \sigma_{\mathrm{T}} / \mathrm{d} \varepsilon_{\mathrm{T}}-\varepsilon_{\mathrm{T}}$ relation refers to the predicted irreversible tensile strain $\varepsilon_{\mathrm{T}, \text { irr }}$ for critical current. The dotted curve in $\left(\mathrm{a}^{\prime}\right)$ shows the regression curve of the $\mathrm{d} \sigma_{\mathrm{T}} / \mathrm{d} \varepsilon_{\mathrm{T}}-\varepsilon_{\mathrm{T}}$ relation in the range of $\varepsilon_{\mathrm{T}}=0.37-0.41 \%\left[>\left(\varepsilon_{\mathrm{f}}-\varepsilon_{\mathrm{r}}\right)_{\mathrm{d}-\mathrm{ini}}(0.37 \%)\right]$.

The $\left(\varepsilon_{\mathrm{f}}-\varepsilon_{\mathrm{r}}\right)_{\mathrm{d}-\mathrm{ini}}$ values are in good agreement with the experimental irreversible tensile strains $\left(\varepsilon_{\mathrm{T}, \text { irr }}\right)$ for critical current. This result shows that the irreversible tensile strain for critical current can be predicted well from the analysis of the stress-strain curves.

\section{ESTIMATION OF THE DAMAGE STRAIN PARAMETER AT 77 K FOR PREDICTION OF CRITICAL CURRENT-BENDING STRAIN RELATION OF THE VAM1 SAMPLE BENT AT $77 \mathrm{~K}$}

In this sub-section, the applicability of the $\varepsilon_{\mathrm{f}}-\varepsilon_{\mathrm{r}}$ value estimated from the tensile stress-strain curve at $77 \mathrm{~K}$ to the variation in critical current $I_{\mathrm{c}} / I_{\mathrm{c} 0}$ at $77 \mathrm{~K}$ with bending $\varepsilon_{\mathrm{B}}$ of the sample bent at $77 \mathrm{~K}$ is examined by using the data for VAM1 sample, reported by Katagiri et al. ${ }^{23}$

Figure 5(a) shows the reported variation in the $I_{\mathrm{c}} / I_{\mathrm{c} 0}$ with $\varepsilon_{\mathrm{B}}$, in which the $I_{\mathrm{c}} / I_{\mathrm{c} 0}$ value is the average of six specimens. ${ }^{23}$ In this test, the bending strain was given to VAM1 sample at $77 \mathrm{~K}$ and the critical current was measured also at $77 \mathrm{~K}$.

As has been shown in the Sec. IV B, the $\left(\varepsilon_{\mathrm{f}}-\varepsilon_{\mathrm{r}}\right)_{\mathrm{d}-\text {-ini }}$ at damage initiation at $77 \mathrm{~K}$ of VAM1 sample was $0.37 \%$. First, this value was substituted into Eq. (3) based on model $\mathrm{S}$ and the $I_{\mathrm{c}} / I_{\mathrm{c} 0}-\varepsilon_{\mathrm{B}}$ relation was calculated. The result is presented with a broken curve in Fig. $5(\mathrm{a})$. The calculated $I_{\mathrm{c}} / I_{\mathrm{c} 0}-\varepsilon_{\mathrm{B}}$ curve describes fairly well the experimental result, indicating that the $\left(\varepsilon_{\mathrm{f}}-\varepsilon_{\mathrm{r}}\right)_{\mathrm{d} \text {-ini }}$ value estimated from the stress-strain curve can be used for prediction as a first approximation. However, the predicted relation is slightly lower than the experimental one, due to the following reason.
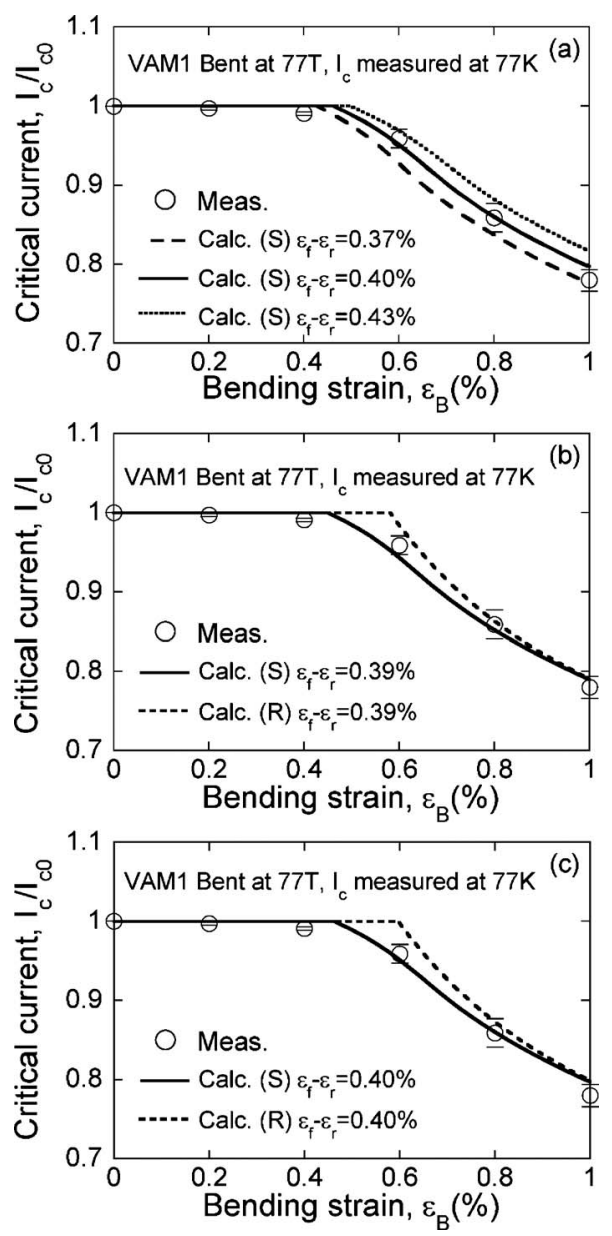

FIG. 5. Comparison of the calculated normalized critical current $I_{\mathrm{c}} / I_{\mathrm{c} 0}$ (measured at $77 \mathrm{~K}$ )-bending strain $\varepsilon_{\mathrm{B}}$ (bent at $77 \mathrm{~K}$ ) curves of the VAM1 sample with the experimental result reported by Katagiri et al. (Ref. 23). (a) Calculated by Eq. (3) (model S) with the damage strain parameter values of $\varepsilon_{\mathrm{f}}-\varepsilon_{\mathrm{r}}=0.37 \%, 0.40 \%$, and $0.43 \%$. (b) Calculated by Eq. (3) (model S) and Eq. (4) (model R) with $\varepsilon_{\mathrm{f}}-\varepsilon_{\mathrm{r}}=0.39 \%$. (c) Calculated by Eqs. (3) and (4) with $\varepsilon_{\mathrm{f}}-\varepsilon_{\mathrm{r}}=0.40 \%$.

In actual specimens, there exist the sections with high and low $\varepsilon_{\mathrm{f}}-\varepsilon_{\mathrm{r}}$ values. ${ }^{12,23,27,28}$ In the tensile test, the weakest section with the lowest $\varepsilon_{\mathrm{f}}-\varepsilon_{\mathrm{r}}$ value in the whole volume of the core is damaged first. The $\left(\varepsilon_{\mathrm{f}}-\varepsilon_{\mathrm{r}}\right)_{\mathrm{d} \text {-ini }}$ value, taken from the tensile stress-strain curve, stems from such a weakest region. On the other hand, in the bending test, the damage takes place first at the outermost Bi2223 filament $\left[y_{\text {core,max }}(\mathbf{S})\right.$ in Fig. 2(a)]. The outermost filament is not necessary the weakest one. Thus, the $\left(\varepsilon_{\mathrm{f}}-\varepsilon_{\mathrm{r}}\right)_{\mathrm{d}-\mathrm{ini}}$ of the weakest portion leads to underestimation of $I_{\mathrm{c}} / I_{\mathrm{c} 0}-\varepsilon_{\mathrm{B}}$ relation. For description of $I_{\mathrm{c}} / I_{\mathrm{c} 0}-\varepsilon_{\mathrm{B}}$ relation, the $\varepsilon_{\mathrm{f}}-\varepsilon_{\mathrm{r}}$ value higher than $\left(\varepsilon_{\mathrm{f}}-\varepsilon_{\mathrm{r}}\right)_{\mathrm{d} \text {-ini }}$ is suitable.

The $\varepsilon_{\mathrm{f}}-\varepsilon_{\mathrm{r}}$ value that can describe the experimental results of $I_{\mathrm{c}} / I_{\mathrm{c} 0}-\varepsilon_{\mathrm{B}}$ relation of VAM1 [Fig. 5(a)] was estimated as follows. The $I_{\mathrm{c}} / I_{\mathrm{c} 0}-\varepsilon_{\mathrm{B}}$ relation was calculated with model $\mathrm{S}$ by substituting $\varepsilon_{\mathrm{f}}-\varepsilon_{\mathrm{r}}=0.40$ and $0.43 \%$ which were slightly higher than $\left(\varepsilon_{\mathrm{f}}-\varepsilon_{\mathrm{r}}\right)_{\mathrm{d} \text {-ini }}=0.37 \%$. The calculation result is presented in Fig. 5(a). In the case of $\varepsilon_{\mathrm{f}}-\varepsilon_{\mathrm{r}}=0.40 \%$, the experimental result is well described. In the case of $\varepsilon_{\mathrm{f}}$ $-\varepsilon_{\mathrm{r}}=0.43 \%$, the calculation result is slightly higher than the experimental result. Thus, it was found that the suitable $\varepsilon_{\mathrm{f}}$ $-\varepsilon_{\mathrm{r}}$ value to describe the $I_{\mathrm{c}} / I_{\mathrm{c} 0}-\varepsilon_{\mathrm{B}}$ relation is around $0.40 \%$. 
The calculation results for $\varepsilon_{\mathrm{f}}-\varepsilon_{\mathrm{r}}=0.39$ and $0.40 \%$ by models $\mathrm{S}$ and $\mathrm{R}$ are shown in Figs. 5(b) and 5(c). The experimental results are well described by model $\mathrm{S}$ for $\varepsilon_{\mathrm{f}}-\varepsilon_{\mathrm{r}}$ $=0.39$ and $0.40 \%$. It is noted that, in comparison with model $\mathrm{S}$, model $\mathrm{R}$ also gives the similar results at high $\varepsilon_{\mathrm{B}}(0.8$ and $1.0 \%$ ), while it leads to overestimation for $I_{\mathrm{c}} / I_{\mathrm{c} 0}$ at low $\varepsilon_{\mathrm{B}}$ $(<0.6 \%)$. It is noted that model $\mathrm{R}$ is easy to calculate and is a practically useful model for description of the $I_{\mathrm{c}} / I_{\mathrm{c} 0}-\varepsilon_{\mathrm{B}}$ relation at high $\varepsilon_{\mathrm{B}}$ range.

As shown above, slightly higher $\varepsilon_{\mathrm{f}}-\varepsilon_{\mathrm{r}}$ value than $\left(\varepsilon_{\mathrm{f}}-\varepsilon_{\mathrm{r}}\right)_{\mathrm{d} \text {-ini }}$ is suitable for description of $I_{\mathrm{c}} / I_{\mathrm{c} 0}-\varepsilon_{\mathrm{B}}$ relation. As a next step, it was attempted to find a suitable $\varepsilon_{\mathrm{f}}-\varepsilon_{\mathrm{r}}$ value from the $\mathrm{d} \sigma_{\mathrm{T}} / \mathrm{d} \varepsilon_{\mathrm{T}}-\varepsilon_{\mathrm{T}}$ curve in an empirical manner as follows. First we approximated the $\mathrm{d} \sigma_{\mathrm{T}} / \mathrm{d} \varepsilon_{\mathrm{T}}-\varepsilon_{\mathrm{T}}$ relation in the range of $\varepsilon_{\mathrm{T}}(0.31 \%-0.37 \%)<\left(\varepsilon_{\mathrm{f}}-\varepsilon_{\mathrm{r}}\right)_{\mathrm{d} \text {-ini }}(0.37 \%)$ [Fig. $\left.4\left(\mathrm{a}^{\prime}\right)\right]$ to be linear and was extrapolated such a linear relation to the higher $\varepsilon_{\mathrm{T}}$ region beyond $\left(\varepsilon_{\mathrm{f}}-\varepsilon_{\mathrm{r}}\right)_{\mathrm{d}-\text { ini }}(0.37 \%)$. Also, as the $\mathrm{d} \sigma_{\mathrm{T}} / \mathrm{d} \varepsilon_{\mathrm{T}}-\varepsilon_{\mathrm{T}}$ relation in the range of $\varepsilon_{\mathrm{T}}(0.37 \%$ $-0.41 \%)\left(>\left(\varepsilon_{\mathrm{f}}-\varepsilon_{\mathrm{r}}\right)_{\mathrm{d}-\mathrm{ini}}(0.37 \%)\right)$ had irregularities, a regression curve was derived as shown with the dotted curve in Fig. 4( $\left.\mathrm{a}^{\prime}\right)$. Then, as the $I_{\mathrm{c}} / I_{\mathrm{c} 0}-\varepsilon_{\mathrm{B}}$ relation was described well with $\varepsilon_{\mathrm{f}}-\varepsilon_{\mathrm{r}}=0.39 \%$ and $0.40 \%$ [Figs. 5(b) and 5(c)], the difference $\Delta$ in $\mathrm{d} \sigma_{\mathrm{T}} / \mathrm{d} \varepsilon_{\mathrm{T}}$ values between the regression curve and the extrapolated one at $\varepsilon_{\mathrm{T}}\left(\varepsilon_{\mathrm{f}}-\varepsilon_{\mathrm{r}}\right)=0.39 \%$ and $0.40 \%$ [Fig. $4\left(\mathrm{a}^{\prime}\right)$ ] were read. The differences $(\Delta)$ were $8 \%$ and $13 \%$ at $\varepsilon_{\mathrm{T}}\left(\varepsilon_{\mathrm{f}}-\varepsilon_{\mathrm{r}}\right)=0.39 \%$ and $0.40 \%$, respectively. From this result, it was suggested that the $\varepsilon_{\mathrm{T}}$ value, at which the $\mathrm{d} \sigma_{\mathrm{T}} / \mathrm{d} \varepsilon_{\mathrm{T}}$ value is reduced by around $10 \%$ in comparison with the extrapolated value, is suitable as the $\varepsilon_{\mathrm{f}}-\varepsilon_{\mathrm{r}}$ value for prediction of $I_{\mathrm{c}} / I_{\mathrm{c} 0}-\varepsilon_{\mathrm{B}}$ relation. This result will be used in Sec. VI to describe the $I_{\mathrm{c}} / I_{\mathrm{c} 0}-\varepsilon_{\mathrm{B}}$ relation of the samples bent at room temperature and cooled down to $77 \mathrm{~K}$ for measurement of critical current.

\section{ESTIMATION OF THE DAMAGE STRAIN PARAMETER AT ROOM TEMPERATURE AND ITS APPLICATION TO PREDICTION OF CRITICAL CURRENT-BENDING STRAIN RELATION OF THE SAMPLES BENT AT ROOM TEMPERATURE}

In this sub-section, the tensile stress-strain curves measured at room temperature are used for prediction of the $I_{\mathrm{c}} / I_{\mathrm{c} 0}-\varepsilon_{\mathrm{B}}$ relation in which the bending strain was given to the samples at room temperature and critical currents were measured at $77 \mathrm{~K}$.

Figure 6 shows the measured tensile stress-strain curves of (a) VAM1, (b) VAM2, and (c) VAM3 samples at room temperature. The stress $\left(\sigma_{\mathrm{T}}\right)$-strain $\left(\varepsilon_{\mathrm{T}}\right)$ curve and the slope $\mathrm{d} \sigma_{\mathrm{T}} / \mathrm{d} \varepsilon_{\mathrm{T}}$ of the regions surrounded by the rectangles in (a), (b), and (c), where damages initiate and extend, are presented at high magnification in $\left(a^{\prime}\right),\left(b^{\prime}\right)$, and $\left(c^{\prime}\right)$, respectively. In the case of tensile test at $77 \mathrm{~K}$ Figs. $3\left(\mathrm{a}^{\prime}\right)-3\left(\mathrm{c}^{\prime}\right)$, the $\mathrm{d} \sigma_{\mathrm{T}} / \mathrm{d} \varepsilon_{\mathrm{T}}-\varepsilon_{\mathrm{T}}$ curve just beyond the $\left(\varepsilon_{\mathrm{f}}-\varepsilon_{\mathrm{r}}\right)_{\mathrm{d} \text {-ini }}\left(\varepsilon_{\mathrm{T}}=0.37\right.$ to $0.40 \%$ for VAM1, $\varepsilon_{\mathrm{T}}=0.40$ to $0.43 \%$ for VAM 2 and $\varepsilon_{\mathrm{T}}=0.32$ to $0.35 \%$ for VAM3) showed the convex. On the other hand, in the case of tensile test at room temperature [Figs. $6\left(\mathrm{a}^{\prime}\right)-6\left(\mathrm{c}^{\prime}\right)$ ], the $\mathrm{d} \sigma_{\mathrm{T}} / \mathrm{d} \varepsilon_{\mathrm{T}}-\varepsilon_{\mathrm{T}}$ curve just beyond the $\left(\varepsilon_{\mathrm{f}}-\varepsilon_{\mathrm{r}}\right)_{\mathrm{d}-\text { ini }}$ in VAM1 and VAM $2\left(\varepsilon_{\mathrm{T}}=0.25 \%\right.$ to $0.28 \%$ for VAM 1 and $\varepsilon_{\mathrm{T}}=0.31 \%$ to $0.35 \%$ for VAM2) showed the concave in contrast to the convex at $77 \mathrm{~K}$, while that in VAM3
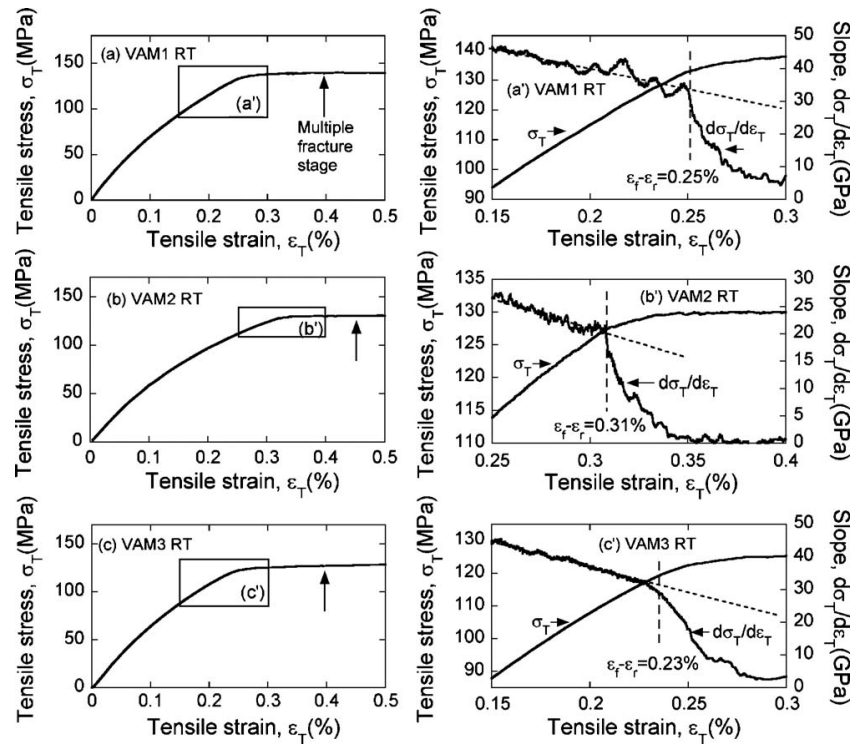

FIG. 6. Measured tensile stress $\left(\sigma_{\mathrm{T}}\right)$-strain $\left(\varepsilon_{\mathrm{T}}\right)$ curves of (a) VAM1, (b) VAM2, and (c) VAM3 samples at room temperature. The arrows show the stage of multiple fracture of the Bi2223 filaments. The stress-strain curve and the slope $\mathrm{d} \sigma_{\mathrm{T}} / \mathrm{d} \varepsilon_{\mathrm{T}}$ of the regions surrounded by the rectangles in (a), (b), and (c), where damages initiate and extend, are presented at high magnification in $\left(a^{\prime}\right),\left(b^{\prime}\right)$, and $\left(c^{\prime}\right)$, respectively.

$\left(\varepsilon_{\mathrm{T}}=0.23 \%\right.$ to $\left.0.25 \%\right)$ showed a convex as well as at $77 \mathrm{~K}$. In this way, the temperature-dependence of the tensile fracture behavior of the Bi2223 filaments was different among the samples.

Due to the concave in the $\mathrm{d} \sigma_{\mathrm{T}} / \mathrm{d} \varepsilon_{\mathrm{T}}-\varepsilon_{\mathrm{T}}$ curve at room temperature of VAM1 and VAM2 samples, the $\varepsilon_{\mathrm{f}}-\varepsilon_{\mathrm{r}}$ value at initiation of the damage and that at $10 \%$ reduction in $\mathrm{d} \sigma_{\mathrm{T}} / \mathrm{d} \varepsilon_{\mathrm{T}}$ were almost the same practically. The $\varepsilon_{\mathrm{f}}-\varepsilon_{\mathrm{r}}$ values for prediction of $I_{\mathrm{c}} / I_{\mathrm{c} 0}-\varepsilon_{\mathrm{B}}$ relation were estimated to be $0.25 \%$ and $0.31 \%$ for VAM1 and VAM 2 samples, respectively. On the other hand, for the VAM3 sample with a convex in the $\mathrm{d} \sigma_{\mathrm{T}} / \mathrm{d} \varepsilon_{\mathrm{T}}-\varepsilon_{\mathrm{T}}$ curve, the $\varepsilon_{\mathrm{f}}-\varepsilon_{\mathrm{r}}$ value for prediction of $I_{\mathrm{c}} / I_{\mathrm{c} 0}-\varepsilon_{\mathrm{B}}$ relation was estimated to be $0.24 \%$ from the $\varepsilon_{\mathrm{T}}$ value at $10 \%$ reduction in $\mathrm{d} \sigma_{\mathrm{T}} / \mathrm{d} \varepsilon_{\mathrm{T}}$ value.

Substituting the $\varepsilon_{\mathrm{f}}-\varepsilon_{\mathrm{r}}$ values $(0.25 \%, 0.31 \%$, and $0.24 \%$ for VAM1, VAM2, and VAM3 samples, respectively) into Eqs. (3) and (4), the $I_{\mathrm{c}} / I_{\mathrm{c} 0}-\varepsilon_{\mathrm{B}}$ curves were calculated and compared with the experimental results, as shown in Fig. 7. In all samples, the experimental results are well described by model $\mathrm{S}$ for the whole bending strain range investigated and by model $\mathrm{R}$ for high bending strain range $\left(\varepsilon_{\mathrm{B}}\right.$ $=0.8 \%-1.0 \%)$.

The present results suggest that the $I_{\mathrm{c}} / I_{\mathrm{c} 0}-\varepsilon_{\mathrm{B}}$ curve can be predicted from the $\mathrm{d} \sigma_{\mathrm{T}} / \mathrm{d} \varepsilon_{\mathrm{T}}-\varepsilon_{\mathrm{T}}$ curve at the temperature where the bending strain was given to the samples. The important finding in this sub-section is that there arise two patterns in the shape of the $\mathrm{d} \sigma_{\mathrm{T}} / \mathrm{d} \varepsilon_{\mathrm{T}}-\varepsilon_{\mathrm{T}}$ curve just beyond the $\left(\varepsilon_{\mathrm{f}}-\varepsilon_{\mathrm{r}}\right)_{\mathrm{d}-\mathrm{ini}}$, depending on the test temperature and fabrication route. One has a convex and another has a concave. When the $\mathrm{d} \sigma_{\mathrm{T}} / \mathrm{d} \varepsilon_{\mathrm{T}}-\varepsilon_{\mathrm{T}}$ curve shows a concave [Figs. 6(a') and $\left.\left(\mathrm{b}^{\prime}\right)\right]$, the $\left(\varepsilon_{\mathrm{f}}-\varepsilon_{\mathrm{r}}\right)_{\mathrm{d}-\mathrm{ini}}$ value gives very close prediction for $I_{\mathrm{c}} / I_{\mathrm{c} 0}-\varepsilon_{\mathrm{B}}$ curve [Figs. 7(a) and 7(b)]. On the other hand, for the samples whose $\mathrm{d} \sigma_{\mathrm{T}} / \mathrm{d} \varepsilon_{\mathrm{T}}-\varepsilon_{\mathrm{T}}$ curves have convex, the $\left(\varepsilon_{\mathrm{f}}-\varepsilon_{\mathrm{r}}\right)_{\mathrm{d}-\text { ini }}$ gives underestimation for the $I_{\mathrm{c}} / I_{\mathrm{c} 0}-\varepsilon_{\mathrm{B}}$ curve 

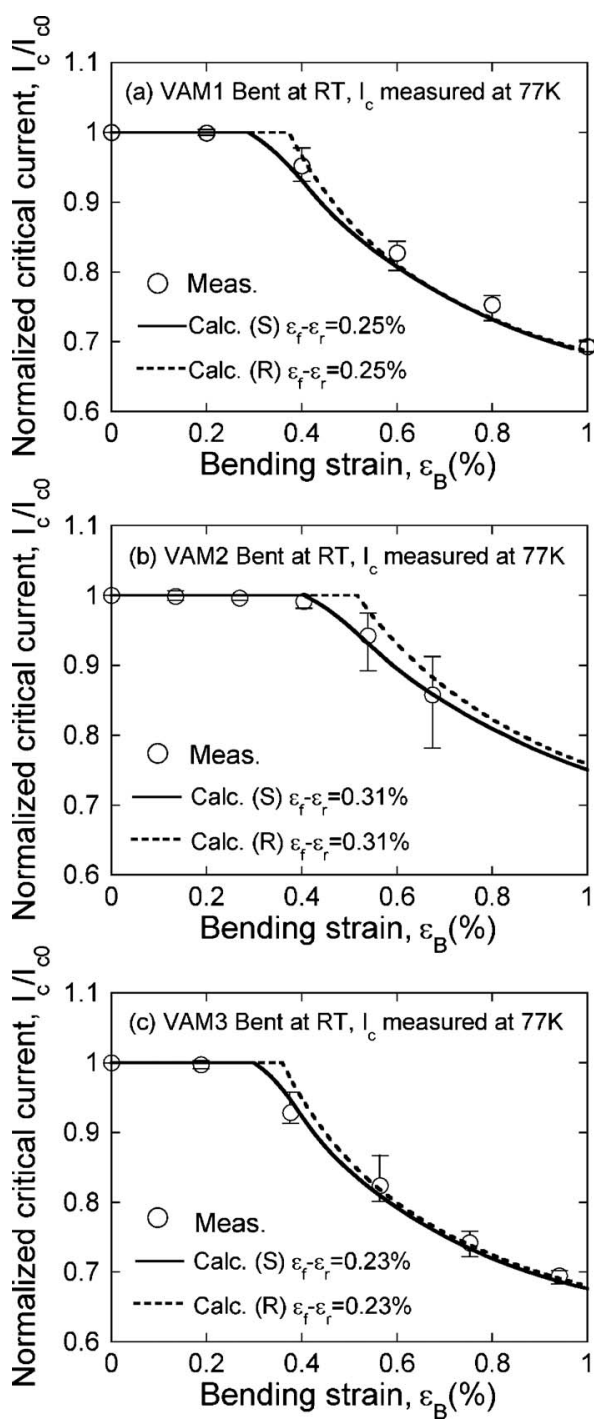

FIG. 7. Comparison of the calculated relation of the normalized critical current $I_{\mathrm{c}} / I_{\mathrm{c} 0}$ to the bending stain $\varepsilon_{\mathrm{B}}$ (bent at room temperature) with the measured one for (a) VAM1, (b) VAM2, and (c) VAM3 samples. The open circle, upper bar, and lower bar at each applied bending strain show the average, the highest, and lowest $I_{\mathrm{c}} / I_{\mathrm{c} 0}$-values of three test specimens. The solid and broken curves show the calculation result with the estimated $\varepsilon_{f}$ $-\varepsilon_{\mathrm{r}}$ value for each sample by models $\mathrm{S}$ and $\mathrm{R}$, respectively.

and the $\varepsilon_{\mathrm{T}}$ value at $10 \%$ reduction in $\mathrm{d} \sigma_{\mathrm{T}} / \mathrm{d} \varepsilon_{\mathrm{T}}$ value could be used as the $\varepsilon_{\mathrm{f}}-\varepsilon_{\mathrm{r}}$ value as a first approximation, though further study is needed to refine this value.

The present work showed that the irreversible tensile strain for critical current can be predicted directly from the tensile stress-strain curve, and critical current-bending strain relation can be predicted also from the tensile stress-strain curve in combination with core shape-incorporated model (model S). The procedure of the present approach is simple. In the case of rough prediction of critical current-bending strain relation, model $\mathrm{R}$ can also be used, with which the calculation becomes far simpler. Model $\mathrm{R}$ is useful for prediction of critical current value especially at high bending strain, giving nearly the same results as model S. The present approach could be a useful tool in practice for prediction of critical current-dependence on applied tensile/bending strain.

\section{CONCLUSIONS}

(1) The damage strain parameter $\left(\varepsilon_{\mathrm{f}}-\varepsilon_{\mathrm{r}}\right)$ at the damage initiation in Bi2223 filaments can be estimated from the deviation point of the slope of the stress-strain curve. Thus estimated parameter value can be used directly to predict the irreversible strain for critical current under applied tensile strain.

(2) After the initiation of damage, the variation in the slope of the tensile stress-strain curve with strain shows two patterns, depending on the test temperature and fabrication route. One has the convex and another has the concave. In the case of the concave, the damage strain parameter at the damage initiation can be used to predict the critical current-bending strain relation. In the case of the convex, the damage strain parameter at the damage initiation can also be used for prediction as a first approximation but leads to slightly lower critical current value. Within the present work, the damage strain parameter at which the slope is reduced by $10 \%$ could give a better prediction.

\section{ACKNOWLEDGMENTS}

The authors wish to express their gratitude to The Ministry of Education, Culture, Sports, Science and Technology, Japan, for the grant-in-aid for scientific research (no. 22360281).

${ }^{1}$ B. ten Haken, A. Beuink, and H. H. J. ten Kate, IEEE Trans. Appl. Supercond. 7, 2034 (1997).

${ }^{2}$ P. Vase, R. Flükiger, M. Leghissa, and B. Glowacki, Supercond. Sci. Technol. 13, R71 (2000).

${ }^{3}$ H. Kitaguchi, K. Itoh, H. Kumakura, T. Takeuchi, K. Togano, and H. Wada, IEEE Trans. Appl. Supercond. 11, 3058 (2001).

${ }^{4}$ R. Passerini, M. Dhallé, G. Witz, B. Seeber, and R. Flükiger, IEEE Trans. Appl. Supercond. 11, 3018 (2001).

${ }^{5}$ R. Passerini, M. Dhallé, E. Giannini, G. Witz, B. Seeber, and R. Flükiger, Physica C 371, 173 (2002).

${ }^{6}$ R. Passerini, M. Dhallé, B. Seeber, and R. Flükiger, Supercond. Sci. Technol. 15, 1507 (2002).

${ }^{7}$ H. J. N. van Eck, L. Vargas, B. ten Haken, and H. H. J. ten Kate, Supercond. Sci. Technol. 15, 1213 (2002).

${ }^{8}$ H. J. N. van Eck, D. C. van der Laan, M. Dhallé, B. ten Haken, and H. H. J. ten Kate, Supercond. Sci. Technol. 16, 1026 (2003).

${ }^{9}$ D. C. van der Laan, H. J. N. van Eck, B. ten Haken, H. H. J. ten Kate, and J. Schwartz, IEEE Trans. Appl. Supercond. 13, 3534 (2003).

${ }^{10}$ K. Osamura, M. Sugano, and K. Matsumoto, Supercond. Sci. Technol. 16, 971 (2003).

${ }^{11}$ M. Sugano, K. Osamura, and M. Hojo, Supercond. Sci. Technol. 16, 571 (2003).

${ }^{12}$ S. Ochiai, T. Nagai, H. Okuda, S. S. Oh, M. Hojo, M. Tanaka, M. Sugano, and K. Osamura, Supercond. Sci. Technol. 16, 988 (2003).

${ }^{13}$ H. S. Shin and K. Katagiri, Supercond. Sci. Technol. 16, 1012 (2003).

${ }^{14}$ A. Nyilas, K. Osamura, and M. Sugano, Supercond. Sci. Technol. 16, 1036 (2003).

${ }^{15}$ A. Otto, E. J. Harley, and R. Marson, Supercond. Sci. Technol. 18, S308 (2005).

${ }^{16}$ S. Ochiai, H. Rokkaku, M. Morishita, J. K. Shin, S. Iwamoto, H. Okuda, M. Hojo, K. Osamura, M. Sato, A. Otto, E. Harley, and A. Malozemoff, Supercond. Sci. Technol. 20, 202 (2007).

${ }^{17}$ S. Ochiai, J. K. Shin, S. Iwamoto, H. Okuda, S. S. Oh, D. W. Ha, and M. Sato, J. Appl. Phys. 103, 123911 (2008).

${ }^{18}$ H. W. Weijers, J. M. Yoo, B. ten Haken, and J. Schwartz, Physica C 357-360, 1160 (2001).

${ }^{19}$ H. W. Weijers, J. Schwartz, and B. ten Haken, Physica C 372-376, 1364 (2002). 
${ }^{20}$ S. J. Sun, W. Liu, X. P. Chen, M. Y. Li, and Z. Han, Supercond. Sci. Technol. 16, 984 (2003).

${ }^{21}$ K. Itoh, T. Kuroda, and H. Wada, Physica C 382, 7 (2002).

${ }^{22}$ T. Kuroda, K. Itoh, K. Katagiri, W. Goldacker, W. Hessler, B. ten Haken, M. Kiuchi, N. Noto, S. Ochiai, S. Otabe, H. S. Shin, J. Sosnowski, H. Weijers, H. Wada, and K. Kumakura, Physica C 425, 111 (2005).

${ }^{23}$ K. Katagiri, T. Kuroda, H. S. Shin, K. Hiroi, K. Itoh, and H. Wada, Physica C 426-431, 1200 (2005).

${ }^{24}$ M. Hojo, M. Nakamura, M. Tanaka, T. Adachi, M. Sugano, S. Ochiai, and K. Osamura, Supercond. Sci. Technol. 18, S356 (2005).

${ }^{25}$ M. K. Al-Mosawi, B. Xu, C. Beduz, Y. Yang, and N. G. Stephen, J. Phys.: Conf. Ser. 43, 543 (2006).
${ }^{26}$ S. Ochiai, T. Matsuoka, J. K. Shin, H. Okuda, M. Sugano, M. Hojo, and K. Osamura, Supercond. Sci. Technol. 20, 1076 (2007).

${ }^{27}$ S. Ochiai, J. K. Shin, H. Okuda, M. Sugano, M. Hojo, K. Osamura, T. Kuroda, K. Itoh, and H. Wada, Supercond. Sci. Technol. 21, 054002 (2008).

${ }^{28}$ S. Ochiai, M. Fujimoto, J. K. Shin, H. Okuda, S. S. Oh, and D. W. Ha, J. Appl. Phys. 106, 103916 (2009).

${ }^{29}$ S. Ochiai, Mechanical Properties of Metallic Composites (Marcel Dekker, New York, 1993), p. 473.

${ }^{30}$ A. Kelly and W. R. Tyson, J. Mech. Phys. Solids 13, 329 (1965).

${ }^{31}$ S. Ochiai, T. Sawada, and M. Hojo, Sci. Eng. Compos. Mater. 6, 63 (1997). 